\title{
Wider reference ranges of serum thyroid stimu- lating hormone in pregnant Korean women: is it time to stop overtreatment?
}

\author{
Kwanhoon Jo and Dong-Jun Lim
}

Division of Endocrinology and Metabolism, Department of Internal Medicine, College of Medicine, The Catholic University of Korea, Seoul, Korea

Received: April 9, 2018

Accepted: April 13, 2018

\section{Correspondence to} Dong-Jun Lim, M.D.

Division of Endocrinology and Metabolism, Department of Internal Medicine, College of Medicine, Seoul St. Mary's Hospital, The Catholic University of Korea, 222 Banpo-daero, Seocho-gu, Seoul 06591, Korea

Tel: +82-2-2258-6009

Fax: +82-2-599-3589

E-mail:1dj6026@catholic.ac.kr

\section{See Article on Page 552-560}

Thyroid hormones are essential for fetal neurocognitive development and pregnancy maintenance. The fetal thyroid gland does not function until 18 to 20 weeks; thus, the developing fetus relies entirely on maternal thyroid function during this period. In recent years, many clinical studies have been conducted on the effects of maternal thyroid dysfunction, especially subclinical hypothyroidism and hypothyroxinemia, on fetal development and pregnancy outcome. Overt hypothyroidism is associated with increased risk of preterm birth, low birth weight, pregnancy loss, and lower offspring intelligence quotient (IQ) [1]. Subclinical hypothyroidism presenting with normal free thyroxine $\left(\mathrm{FT}_{4}\right)$ and high thyroid stimulating hormone (TSH) levels is associated with relatively mild adverse effects compared to overt hypothyroidism, but should not be ignored owing to its high incidence rate [2].

Factors that affect thyroid function during pregnancy include iodine [3], human chorionic gonadotropin (hCG) concentration [4], the placenta [5], body mass index [6], and ethnicity [7]. As thyroid physiology changes during pregnancy due to these factors, each trimes- ter should have its own TSH reference range based on the population of pregnant women. The American Thyroid Association (ATA) clinical management guidelines [8], published in 2011, provided stricter cutoff values of TSH, different from those of the general population. In accordance with this suggestion, the 2014 Guidelines for the Diagnosis and Management of Thyroid Disease during Pregnancy and Postpartum by the Korean Thyroid Association [9] recommends TSH reference values of 0.2 to $2.5 \mathrm{mIU} / \mathrm{L}$ in the first trimester, 0.2 to $3.0 \mathrm{mIU} / \mathrm{L}$ in the second trimester, and 0.30 to $3.5 \mathrm{mIU} / \mathrm{L}$ in the third trimester.

However, these TSH reference values were not derived from studies on pregnant Korean women; the reference ranges of thyroid hormones in most clinical guidelines are based on studies of Caucasian subjects. The Korean population has a higher iodine intake than Caucasian populations; thus, the TSH levels of Korean women are likely to be higher than those of women in other countries. For this reason, trimester-specific TSH reference ranges should be obtained for the Korean population.

In the current issue, Kim et al. [10] investigated the reference values of 
thyroid hormones in pregnant Korean women. This study was conducted on pregnant women screened at a single center, without evidence of thyroid disease and without factors that could affect thyroid function, including thyroid autoantibodies. Thyroid hormone profiles, including serum TSH and FT4 levels, along with anti-thyroid peroxidase (anti-TPO) antibodies and anti-thyroglobulin (anti-Tg) antibodies, were measured in all patients, and urine iodine concentration (UIC) was measured in some of the subjects. Pregnancy and perinatal outcomes including pregnancy hypertension, preeclampsia, and neonatal malformation were evaluated according to maternal thyroid function. The UIC was more than adequate, and the TSH reference value during the first trimester comprised a wider range ( 0.03 to $4.24 \mathrm{mIU} / \mathrm{L}$ ) than the reference values presented in the previous guidelines ( 0.1 to $2.5 \mathrm{mIU} / \mathrm{L}$ ). Additionally, there were no significant differences in pregnancy and perinatal outcomes between the patients with subclinical, euthyroid, or isolated hypothyroxinemia, probably because the number of study subjects was too small to discriminate the final outcomes of each condition.

Choi et al. [11] showed that when the median TSH levels obtained from hospital-based pregnant Korean women like those in this study were applied, the pro- portion of patients with subclinical hypothyroidism was reduced to one-third of the proportion based on the ATA guidelines (from $14.7 \%$ to $5.0 \%$ ). This was a largescale study of more than 8,000 mothers, but there were no data on thyroid autoantibodies or iodine status, and it was a retrospective study; therefore, it is difficult to determine whether some patients with thyroid disease were completely excluded. In another study conducted in pregnant Korean women, Moon et al. [12] also reported broader TSH reference ranges for the first trimester ( 0.01 to $4.10 \mathrm{mIU} / \mathrm{L}$ ) than those in the ATA guidelines, similar to the findings of this study. However, there were also no data on iodine status, an important factor in determining thyroid function. One study conducted in China [13], a country rich in iodine, and two studies conducted in India $[14,15]$ also found that the upper limits of the reference ranges (ULRR) of TSH levels were higher than those of western countries (Table 1) [8-17].

It is probably important to increase the ULRR of TSH levels in pregnant women because it reduces the proportion of those who receive thyroid hormone therapy. In one study, levothyroxine treatment in pregnant patients with subclinical hypothyroidism increased maternal $\mathrm{T}_{4}$ levels, which may lower the IQ and cortex volume of the brains of offspring, owing to overtreatment (although in

Table 1. Thyroid stimulating hormone reference ranges of pregnant women in their first trimester from various studies of iodine-replete areas and clinical guidelines

\begin{tabular}{|c|c|c|c|c|}
\hline Guidelines or clinical studies & $\begin{array}{c}\text { First trimester, } \mathrm{mIU} / \mathrm{L} \\
(2.5 \mathrm{th}-97.5 \mathrm{th})\end{array}$ & $\begin{array}{c}\text { Thyroid antibodies } \\
\text { or US evaluation }\end{array}$ & Iodine status ${ }^{\mathrm{a}}$ & Country \\
\hline ATA guideline (2011) [16] & $0.1-2.5$ & - & - & USA \\
\hline ETA guideline (2014) [17] & p range br $^{\text {or }} \leq 2.5$ & - & - & Europe \\
\hline KTA guideline (2014) [9] & $0.1-2.5$ & - & - & Korea \\
\hline ATA guideline (2017) [8] & p range ${ }^{b}$ or $\leq 4$ & - & - & USA \\
\hline Marwaha et al. (2008) [14] & $0.60-5.0$ & $\mathrm{Ab}(+) \mathrm{US}(+)^{\mathrm{c}}$ & NA & India \\
\hline Li et al. (2014) [13] & $0.10-4.34$ & $\mathrm{Ab}(+) \mathrm{US}(-)$ & Adequate & China \\
\hline Moon et al. (2015) [12] & $0.01-4.10$ & $\mathrm{Ab}(+) \mathrm{US}(-)$ & NA & Korea \\
\hline Sekhri et al. (2016) [15] & $0.09-6.65$ & $\mathrm{Ab}(+) \mathrm{US}(-)$ & Adequate & India \\
\hline Choi et al. (2017) [11] & $\leq 3.66$ & $\mathrm{Ab}(-) \mathrm{US}(-)$ & NA & Korea \\
\hline Kim et al. (2018) [10] & $0.03-4.24$ & $\mathrm{Ab}(+) \mathrm{US}(-)$ & More-than-adequate & Korea \\
\hline
\end{tabular}

US, ultrasound; $\mathrm{Ab}$, antibody; NA, not available.

${ }^{a}$ Iodine status (median urinary iodine concentration) recommendation by World Health Organization: 150-249 $\mu \mathrm{g} / \mathrm{L}$, adequate; 250-499 $\mathrm{g} / \mathrm{L}$, more-than-adequate; $\geq 500 \mu \mathrm{g} / \mathrm{L}$, excessive.

${ }^{\mathrm{b}} \mathrm{p}$ range: population-based trimester-specific reference range.

${ }^{\mathrm{c}} \mathrm{Ab}(+)$, thyroid auto-antibody (anti-thyroid peroxidase antibody and anti-thyroglobulin antibody) evaluation was done; US (+), thyroid ultrasound evaluation was done. 
this study, maternal TSH concentrations were not associated with child IQ) [18]. Therefore, if the TSH ULRR of the first trimester was increased from 2.5 to $4 \mathrm{mIU} / \mathrm{L}$ [8], or to the ULRR of this study (4.24 mIU/L), many mothers would be re-classified to euthyroid status in the new reference ranges who may otherwise have been classified with subclinical hypothyroidism according to the ATA guidelines (from $25.2 \%$ to $3.0 \%$ ). This may reduce the potential harm caused by levothyroxine treatment.

As previously mentioned, several studies have reported adverse outcomes in subclinical hypothyroid women, but those were limited by the heterogeneity and small sample sizes of the included studies. A meta-analysis of 15 studies showed that subclinical hypothyroidism or isolated hypothyroxinemia had no effects on preterm birth [19], and this study showed the same result.

When defining the standard population for obtaining TSH reference ranges, the presence of thyroid autoantibodies should be excluded. Thyroid autoimmunity, which is reflected by the presence of anti-TPO and anti-Tg antibodies, is a major risk factor for subclinical hypothyroidism. There is a higher risk of adverse pregnancy outcome in pregnant subjects with subclinical hypothyroidism and anti-TPO antibodies, as compared with euthyroid anti-TPO antibody-positive mothers or those with subclinical hypothyroidism without anti-TPO antibodies (even when thyroid function is the same) [20]. In this sense, there was a report that levothyroxine-treated euthyroid mothers with anti-TPO antibodies had a significantly lower rate of preterm delivery than untreated mothers [21]. As the presence of anti-TPO antibodies is associated with a blunted response of thyroid hormone to HCG stimulation, recent ATA guidelines recommend that anti-TPO antibody levels should be checked if TSH levels are found to be above $2.5 \mathrm{mIU} / \mathrm{L}$ during the first trimester [8]. Further studies are needed to determine the ULRR for trimester-specific TSH levels in anti-TPO antibody-positive mothers.

Although the subjects studied by Kim et al. [10] were in a tertiary hospital and not a population cohort, and the study results were unable to confirm the perinatal outcomes of all of the mothers so it is unlikely to be generalizable to all pregnant Korean women, concordant results with previous studies and clinical guidelines, including trimester-specific TSH reference values and iodine status, were suggested by the study. Therefore, further long-term population-based interventional follow-up studies including the outcomes of offspring and mothers are needed to confirm the clinical implications of subclinical hypothyroidism during initial pregnancy.

\section{Conflict of interest}

No potential conflict of interest relevant to this article was reported.

\section{REFERENCES}

1. Leung AS, Millar LK, Koonings PP, Montoro M, Mestman JH. Perinatal outcome in hypothyroid pregnancies. Obstet Gynecol 1993;81:349-353.

2. Maraka S, Ospina NM, O'Keeffe DT, et al. Subclinical hypothyroidism in pregnancy: a systematic review and meta-analysis. Thyroid 2016;26:580-590.

3. Shi X, Han C, Li C, et al. Optimal and safe upper limits of iodine intake for early pregnancy in iodine-sufficient regions: a cross-sectional study of 7190 pregnant women in China. J Clin Endocrinol Metab 2015;100:1630-1638.

4. Glinoer D, de Nayer P, Bourdoux P, et al. Regulation of maternal thyroid during pregnancy. J Clin Endocrinol Metab 1990;71:276-287.

5. Romero R, Nien JK, Espinoza J, et al. A longitudinal study of angiogenic (placental growth factor) and anti-angiogenic (soluble endoglin and soluble vascular endothelial growth factor receptor-1) factors in normal pregnancy and patients destined to develop preeclampsia and deliver a small for gestational age neonate. J Matern Fetal Neonatal Med 2008;21:9-23.

6. Oliveira FT, Salvatori R, Marcondes J, et al. Altered sleep patterns in patients with non-functional GHRH receptor. Eur J Endocrinol 2017;177:51-57.

7. La'ulu SL, Roberts WL. Ethnic differences in first-trimester thyroid reference intervals. Clin Chem 2011;57:913-915.

8. Alexander EK, Pearce EN, Brent GA, et al. 2017 Guidelines of the American Thyroid Association for the diagnosis and management of thyroid disease during pregnancy and the postpartum. Thyroid 2017;27:315-389.

9. Yi KH, Kim KW, Yim CH, et al. Guidelines for the diagnosis and management of thyroid disease during pregnancy and postpartum. J Korean Thyroid Assoc 2014;7:7-39.

10. Kim HJ, Cho YY, Kim SW, et al. Reference intervals of thyroid hormones during pregnancy in Korea, an iodine-re- 
plete area. Korean J Intern Med 2018;33:552-560.

11. Choi HW, Han YJ, Kwak DW, et al. Maternal thyroid function during the first trimester of pregnancy in Korean women. Int J Thyroidol 2017;10:36-41.

12. Moon HW, Chung HJ, Park CM, Hur M, Yun YM. Establishment of trimester-specific reference intervals for thyroid hormones in Korean pregnant women. Ann Lab Med 2015;35:198-204.

13. Li C, Shan Z, Mao J, et al. Assessment of thyroid function during first-trimester pregnancy: what is the rational upper limit of serum TSH during the first trimester in Chinese pregnant women? J Clin Endocrinol Metab 2014;99:73-79.

14. Marwaha RK, Chopra S, Gopalakrishnan S, et al. Establishment of reference range for thyroid hormones in normal pregnant Indian women. BJOG 2008;115:602-606.

15. Sekhri T, Juhi JA, Wilfred R, et al. Trimester specific reference intervals for thyroid function tests in normal Indian pregnant women. Indian J Endocrinol Metab 2016;20:101107.

16. Stagnaro-Green A, Abalovich M, Alexander E, et al. Guidelines of the American Thyroid Association for the diagnosis and management of thyroid disease during pregnancy and postpartum. Thyroid 2011;21:1081-1125.
17. Lazarus J, Brown RS, Daumerie C, Hubalewska-Dydejczyk A, Negro R, Vaidya B. 2014 European Thyroid Association guidelines for the management of subclinical hypothyroidism in pregnancy and in children. Eur Thyroid J 2014;3:76-94.

18. Korevaar TI, Muetzel R, Medici M, et al. Association of maternal thyroid function during early pregnancy with offspring IQ and brain morphology in childhood: a population-based prospective cohort study. Lancet Diabetes Endocrinol 2016;4:35-43.

19. Sheehan PM, Nankervis A, Araujo Junior E, Da Silva Costa F. Maternal thyroid disease and preterm birth: systematic review and meta-analysis. J Clin Endocrinol Metab 2015;100:4325-4331.

20. Nazarpour S, Ramezani Tehrani F, Simbar M, Tohidi M, Alavi Majd H, Azizi F. Effects of levothyroxine treatment on pregnancy outcomes in pregnant women with autoimmune thyroid disease. Eur J Endocrinol 2017;176:253265.

21. van den Boogaard E, Vissenberg R, Land JA, et al. Significance of (sub)clinical thyroid dysfunction and thyroid autoimmunity before conception and in early pregnancy: a systematic review. Hum Reprod Update 2011;17:605-619. 